medRxiv preprint doi: https://doi.org/10.1101/2020.06.09.20126987; this version posted June 16, 2020. The copyright holder for this preprint (which was not certified by peer review) is the author/funder, who has granted medRxiv a license to display the preprint in perpetuity. It is made available under a CC-BY-NC-ND 4.0 International license .

\title{
Consequences of Mismatch, Misalignment and Rotation of Toric Intraocular Lenses in Refractive Cataract Surgery \\ Part 1. It Ain't 30. The True Angle of Doom.
}

\author{
Samir I Sayegh, MD, PhD, FACS \\ The EYE Center, Champaign, IL, USA \\ sayegh@umich.edu
}

\begin{abstract}
Purpose: To demonstrate that the total loss of astigmatism as a consequence of misalignment or rotation of a toric intraocular lens (tIOL) can occur much earlier than the widely believed and taught 30 degrees. To give a precise surgically useful estimate of that value. To clarify the role of mismatch and misalignment of toric intraocular lenses in cataract surgery beyond what is commonly recognized in the literature and make corresponding surgical recommendations.
\end{abstract}

Setting: Private Practice and Research Center. The EYE Center. Champaign, IL, USA.

Design: Formal Analytical Study

Methods: The astigmatism addition approach is used in its simplest form along with analytical tools to derive new results concerning mismatch, misalignment and rotation of toric intraocular lenses.

Results: The often stated results of total loss of astigmatic correction by 30-degree rotation and $3.3 \%$ loss per degree represent a usually poor approximation to realistic surgical cases. We show how they constitute a very special case in the context of a more general framework relevant to procedures performed by refractive cataract surgeons dealing with the surgical correction of astigmatism with tIOLs. Total loss of astigmatic correction can occur with as little as 20 degrees of misalignment and less than 10 degrees of tIOL rotation. A practical approximation for that angle of doom, $\Delta$, in the surgically relevant range can be expressed by $\Delta \approx \mathbf{3 0}-\mathbf{1 5} \boldsymbol{\omega}$ degrees, where $\omega=\frac{\mathrm{L}-\mathrm{A}}{A}$ is the fractional overcorrection of $\mathrm{L}$, the cylinder of the tIOL, and $\mathrm{A}$, the astigmatism to be corrected. Similarly for undercorrection we show that $\Delta \approx \mathbf{3 0}+\mathbf{1 5} \boldsymbol{u}$ degrees where $u=\frac{\mathrm{A}-\mathrm{L}}{A}$ represents the corresponding fractional undercorrection. That is to say the angle of doom is extended beyond the 30 degrees for cases of undercorrection of the astigmatism. We also demonstrate that overcorrection of astigmatism results in a significantly faster decline in astigmatism correction per degree of misalignment/rotation. The significant clinical implications and surgical recommendations, including for optimal degree of overcorrection, are a natural consequence of these novel results.

Conclusions: Total loss of astigmatism correction can occur at a significantly smaller angle than commonly believed and overcorrected astigmatism residual rises with tIOL misalignment or rotation significantly faster than undercorrected astigmatism. We provide the methodology and explicit solution for determining this behavior. 
medRxiv preprint doi: https://doi.org/10.1101/2020.06.09.20126987; this version posted June 16, 2020. The copyright holder for this preprint

(which was not certified by peer review) is the author/funder, who has granted medRxiv a license to display the preprint in perpetuity.

It is made available under a CC-BY-NC-ND 4.0 International license .

\section{INTRODUCTION}

As many as half of patients presenting for cataract surgery can potentially benefit from simultaneous correction of astigmatism, present initially and possibly induced by the procedure ${ }^{1}$. Surgical methods of correcting astigmatism have included limbal relaxing incisions (LRI), corneal incisions and toric intraocular lenses (tIOL). tIOLs have several advantages and have been used increasingly in the past decade. One potential limitation of tIOLs however concerns possible rotation and more generally misalignment due to rotation but also to positioning and initial inaccuracies in the estimate of the cross cylinder astigmatism to be corrected after the incisions have been performed and the procedure completed. Several investigators have looked at the consequences of tIOL rotation or misalignment both theoretically and in actual clinical studies. The occurrence of such tIOL rotations has also been documented by direct and indirect methods since the inception of the field to the present. The significant popularity of an online calculator to analyze the possibility of improving a refractive toric surprise is an indication that in clinical practice the occurrence of such surprises is common ${ }^{2}$. The most common statement concerning the rotation or misalignment of a tIOL is that it loses $100 \%$ of its astigmatic correction effect at 30 degrees of misalignment at the rate of $3.3 \%$ per degree, getting worse afterwards with the residual astigmatism exceeding the initial astigmatism to be corrected $^{34567891011127131415}$. When this statement is made, the underlying assumption is that the magnitude of the cylinder of the tIOL is equal to the magnitude of the astigmatism to be corrected. In surgical practice, the fulfillment of this assumption is neither common nor realistic. One reason is that most tIOLs used in practice have a discrete set of cylinder values. For example, T3, T4, correcting about 1 diopter (D) or $1.5 \mathrm{D}$ of astigmatism at the corneal plane, respectively but nothing in between. Even if the astigmatism to be corrected at the corneal plane were perfectly known, say $1.27 \mathrm{D}$, this would not match the cylinder of either T3 or T4 tIOLs and the usual matching assumption would be immediately violated resulting in undercorrection or overcorrection depending on which tIOL is chosen. A second reason, also relating to the tIOL, is the fact that the ideal toricity ratio may not be used because of limitations of the toric calculator or uncertainty in the effective lens position (ELP), a variable contributing to the toricity ratio and thus to the value of the tIOL cylinder at the corneal plane ${ }^{16}$. Additional reasons, relating to the astigmatism A to be corrected at the corneal plane, include uncertainties on measurements of the magnitude and meridian of its dominant anterior contribution ${ }^{1718}$, uncertainties on the posterior astigmatism, as well as uncertainty on the values of surgical induced astigmatism, with estimates of SIA ranging from zero to half a diopter for similar clear corneal incisions ${ }^{1912}$. All these reasons contribute to a high likelihood of some degree of mismatch between the tIOL cylinder and the estimated astigmatism to be corrected, including different tIOL recommendations by different calculators of the same manufacturer ${ }^{20}$. This is confirmed by the fact that even after perfect (re)alignment, a residual astigmatism of up to or beyond $0.75 \mathrm{D}$, often occurs, and up to $0.75 \mathrm{D}$ is deemed acceptable ${ }^{221}$.

So the question "At what angle of misalignment of the tIOL is the astigmatic correction nullified?" needs a more sophisticated answer. We designate this critical angle of misalignment as the "angle of doom" in analogy to the "triangle of doom," a concept from general surgery suggesting an area to be avoided during hernia repair ${ }^{22}$. Since the inception of the field of tIOLs the common belief has propagated that this angle is equal to 30 degrees. We show that this is a very special case that rarely corresponds to clinical reality. Literature dating back to the $19^{\text {th }}$ and 
medRxiv preprint doi: https://doi.org/10.1101/2020.06.09.20126987; this version posted June 16, 2020. The copyright holder for this preprint (which was not certified by peer review) is the author/funder, who has granted medRxiv a license to display the preprint in perpetuity. It is made available under a CC-BY-NC-ND 4.0 International license .

$20^{\text {th }}$ century establishes the basic method of adding astigmatism and suggests that overcorrection induces more rotational residual astigmatic error ${ }^{2324252627282930}$, which implies that the nullification of an overcorrected astigmatism is reached at an angle smaller than 30 degrees. The concept does not appear to have filtered to modern day refractive cataract surgery with tIOLs with few notable exceptions usually limited to numerical examples ${ }^{29313032}$. A straightforward, full and accurate development of this theme is presented here. In a companion paper we give a rigorous derivation of the optimal degree of overcorrection to be accepted when selecting a tIOL. The corresponding recommendations are somewhat different than those adopted by major tIOL manufacturers or those made recently in the surgical literature ${ }^{33}$.

\section{MATERIALS AND METHODS}

In this study we use simple geometric means to represent the effect and loss of effect of astigmatism corrected via a toric intraocular lens. We also use the simplest possible nomenclatures and representation. To the extent possible we use a single letter to represent a measurement or a physical quantity. Since we will be dealing with the presumed corneal astigmatism to be corrected $\mathrm{A}$, the astigmatism of the correcting tIOL at the corneal plane, $\mathrm{L}$ and the residual astigmatism $\mathrm{R}$, we chose a triangle representation where $\mathrm{L}, \mathrm{R}$ and $\mathrm{A}$ correspond to the length of the three sides, where the angle $2 \lambda$ between $L$ and A in the astigmatism "vector" representation is double the angle $\lambda$ between $\mathrm{L}$ and $\mathrm{A}$ as measured in the eye itself. This "double angle" representation, relevant to differential geometry, optometry and ophthalmology, goes back at least to the $18^{\text {th }}$ and $19^{\text {th }}$ century ${ }^{232425}$ and has been reintroduced to modern refractive cataract surgery in the past decades. With $\mathrm{A}=|\mathrm{A}|, \mathrm{L}=|\mathrm{L}|$ the magnitudes of the "vectors" A and $\mathrm{L}$, will always be considered positive and $\mathrm{R}_{0}=|\mathrm{A}-\mathrm{L}|$ is the magnitude of the mismatch between A and L.

We consider 6 cases as illustrated in Figure 1

1) Perfect alignment and magnitude match. $\lambda=0, L=A . R=R_{0}=0$

2) Perfect alignment with undercorrection. $\lambda=0, \mathrm{~L}<\mathrm{A} . \mathrm{R}=\mathrm{R}_{0}$

3) Perfect alignment with overcorrection. $\lambda=0, L>A$. $R=R_{0}$

4) Misalignment with magnitude match. $\lambda \neq 0 . \mathrm{L}=\mathrm{A}$

5) Misalignment with undercorrection. $\lambda \neq 0 . \mathrm{L}<\mathrm{A}$

6) Misalignment with overcorrection. $\lambda \neq 0$. $L>A$

We do not distinguish between the cases where misalignment is clockwise or counterclockwise as the results are essentially equivalent for the purpose of this analysis. Figure 1 represents the 6 cases as listed.

\begin{tabular}{|l|l|l|l|}
\hline & $\mathrm{L}=\mathrm{A}$ & $\mathrm{L}<\mathrm{A}$ & $\mathrm{L}$ \\
\hline $\mathrm{L}$ and A Aligned \\
Misaligned
\end{tabular}

Figure 1 Six cases illustrating all possibilities of mismatch and misalignment of astigmatism A to be corrected by tIOL cylinder $L$, both at the corneal plane. 
medRxiv preprint doi: https://doi.org/10.1101/2020.06.09.20126987; this version posted June 16, 2020. The copyright holder for this preprint (which was not certified by peer review) is the author/funder, who has granted medRxiv a license to display the preprint in perpetuity.

It is made available under a CC-BY-NC-ND 4.0 International license .

We designate the value of the angle $\lambda$ for which $\mathrm{R}$ becomes equal to $\mathrm{A}$ by $\Delta$, the angle of doom, and we start by illustrating five important points later developed in this paper (Figure 2) :

1) Matched but misaligned $\mathrm{L}$ and $\mathrm{A}$ lead to $\mathrm{R}=\mathrm{A}$ at $\Delta=30$ degrees.

2) Mismatched and misaligned $\mathrm{L}$ and $\mathrm{A}$ give rise to $\mathrm{R}=\mathrm{A}$ at $\Delta>30$ degrees for undercorrection.

3) Mismatched and misaligned $\mathrm{L}$ and $\mathrm{A}$ give rise to $\mathrm{R}=\mathrm{A}$ at $\Delta<30$ degrees for overcorrection.

4) The departure of the value of $\Delta$ from 30 degrees can be very significant.

5) The maximum value of $\Delta$ is 45 degrees.

Consider the case $\mathrm{L}=\mathrm{A}$ and set $\mathrm{R}=\mathrm{A}$. We now have $\mathrm{L}=\mathrm{R}=\mathrm{A}$, and thus an equilateral triangle with all three angles equal and thus $2 \Delta=60$ degrees. $\Delta=30$ degrees. This is the case most commonly cited in the literature.

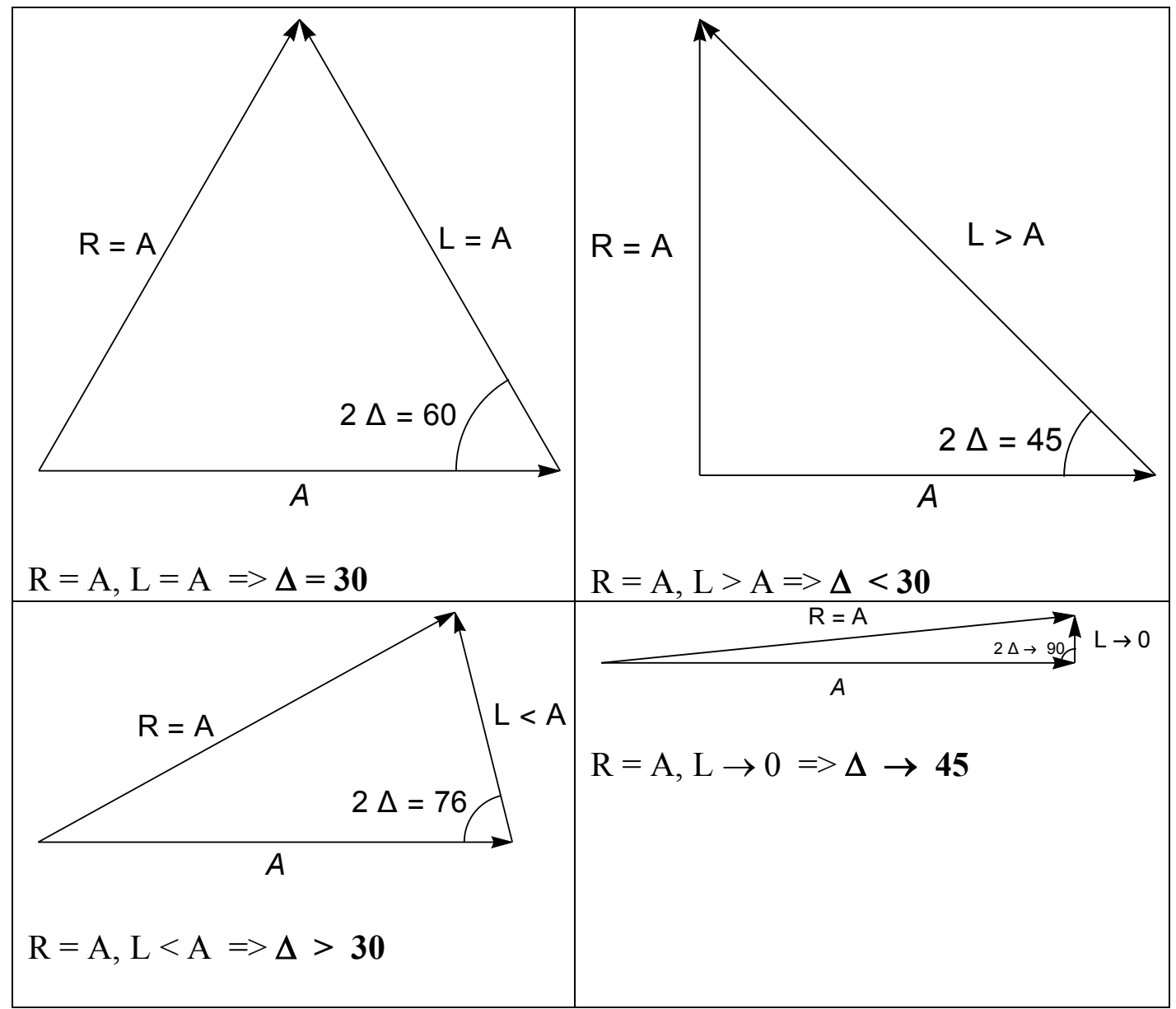

Figure 2: Illustrates the cases of 1) perfect match of $A$ and L resulting in an equilateral triangle and thus $2 \Delta=60$ degrees and $\Delta=30$ degrees, the "classical" result. 2) Overcorrection $L \cong 1.4 \mathrm{~A}$ and $\Delta=22.5$ and 3) Undercorrection $L=0.5 \mathrm{~A}$ and $\lambda \cong 38$ degrees. 4) Limit of "barely toric" IOL with $\Delta \rightarrow 45$ degrees. 
medRxiv preprint doi: https://doi.org/10.1101/2020.06.09.20126987; this version posted June 16, 2020. The copyright holder for this preprint (which was not certified by peer review) is the author/funder, who has granted medRxiv a license to display the preprint in perpetuity.

It is made available under a CC-BY-NC-ND 4.0 International license .

For the case L $>$ A we can rotate L until its tip lays just above the "tail" of A (i.e. has the same horizontal coordinate) the triangle formed by LRA is now a right angle triangle, but the condition $\mathrm{R}=\mathrm{A}$ also makes it isosceles. The two non-right angles are thus each equal to 45 degrees. So $2 \Delta$ $=45$ and $\Delta=22.5$ degrees. The length of $\mathrm{L}$ can be obtained from the Pythagorean theorem and is simply $\sqrt{2} \mathrm{~A} \sim 1.4 \mathrm{~A}$. This illustrates that an overcorrection of about $40 \%$ will result in a drop of $25 \%$ in $\Delta$, and that this angle is actually much closer to 20 than it is to 30 degrees. This presents us with a less tenable surgical scenario, especially if other uncertainties contribute to potential misalignment.

We now illustrate the case of undercorrection. We use $\mathrm{L}=1 / 2 \mathrm{~A}$ and rotate till $\mathrm{R}=\mathrm{A}$. The isosceles triangle with base $\mathrm{L}=1 / 2 \mathrm{~A}$ has angle $2 \Delta \cong 76$ degrees and thus $\Delta \cong 38$ degrees. This demonstrates on an easily visualized example that undercorrection appears to increase the angle of doom. The last triangle case we observe is that of a very thin triangle as L becomes very small and tends to zero. The two equal angles of the isosceles triangle required for the equality of $\mathrm{A}$ and $\mathrm{L}$ remain equal in the limit and now add up to 180 degrees. We thus have $2 \Delta=90$ and $\Delta=45$ degrees. This illustrates the limiting value of $\Delta$.

\section{General Case}

We now analyze the general case using simple trigonometry and elementary algebraic manipulations. A more geometric approach is deferred to a review article.

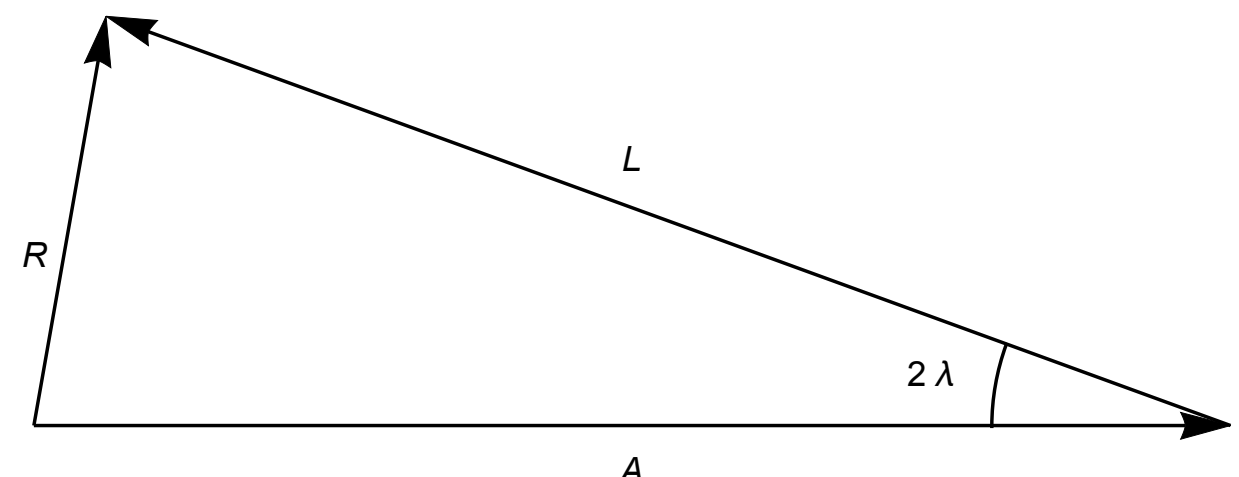

Figure 3. A triangle representation of astigmatism $A$ with an attempted correction $L$ that has rotated by an angle $\lambda$ with respect to the intended meridian, with a residual astigmatism $R$. The geometric representation and residual calculation are based on a triangle with an angle $2 \lambda$ between the sides, $A$ and L. From elementary geometry an "SAS" (side angle side) triangle is uniquely determined and therefore both the residual astigmatism and its meridian are easily computable.

Applying the law of cosines to the ALR triangle of Figure 3, we obtain

$$
R^{2}(\lambda)=A^{2}+L^{2}-2 A L \cos 2 \lambda
$$

This can be rewritten as

$$
\begin{aligned}
R^{2}(\lambda) & =(A-L)^{2}+4 \mathrm{AL} \sin ^{2} \lambda=(A-L)^{2}+4 A(A-A+L) \sin ^{2} \lambda \\
& =(A-L)^{2}+4 A^{2} \sin ^{2} \lambda-4 A(A-L) \sin ^{2} \lambda
\end{aligned}
$$


and eliminating $\mathrm{L}$ in favor of $\mathrm{R}(0)=\mathrm{R}_{0}=|\mathrm{A}-\mathrm{L}|$, we can rewrite

$$
R^{2}=R_{0}^{2}+4 A^{2} \sin ^{2} \lambda-4 A R_{0} \sin ^{2} \lambda
$$

for undercorrection $\mathrm{L}<\mathrm{A}$, and

$$
R^{2}=R_{0}^{2}+4 A^{2} \sin ^{2} \lambda+4 A R_{0} \sin ^{2} \lambda
$$

for overcorrection $\mathrm{L}>\mathrm{A}$

Note the similarities and differences between these two equations ${ }^{1}$.

We take two additional steps to simplify the analysis. We introduce quantities defined relative to the astigmatism A to be corrected. Setting $\mathrm{r}=\frac{R}{A}$ results in

$$
r^{2}=r_{0}^{2}+4 \sin ^{2} \lambda-4 r_{0} \sin ^{2} \lambda
$$

with $\mathrm{r}_{0}=r(0)=\frac{R_{0}}{A}$

representing the fractional mismatch of $\mathrm{L}$ and $\mathrm{A}$ in the case of undercorrection. Similarly we have

$$
r^{2}=r_{0}^{2}+4 \sin ^{2} \lambda+4 r_{0} \sin ^{2} \lambda
$$

for the case of overcorrection.

This representation establishes that the relevant functional variables are ratios. The geometrical equivalent is considering one triangle, with one side having length $=1$, to represent all similar triangles. All "actual" quantities can then be recovered by multiplying by the scaling variable (here A) at the end of the computation. This is the same as a change of unit where all quantities representing optical power are expressed in units of A-diopter instead of diopter, with the conversion factor being $\mathrm{A}$.

We also define the astigmatism having been corrected $\mathrm{S}=\mathrm{A}-\mathrm{R}$ (so if the residual is zero for example then we have $\mathrm{S}=\mathrm{A}$ and the full astigmatism has been corrected), and the fractional (or percentage) astigmatism having been corrected $s$,

\footnotetext{
1 An alternative approach is to define $R_{0}$ as a signed quantity that is positive for undercorrection and negative for overcorrection resulting in one formula encompassing both under and overcorrection. For the remaining of the discussion we opt for the representation where $R_{0}$ is always positive and we keep track separately of over and under correction. This is done for a number of reasons one of them being that a main point of the paper is to explicitly emphasize the distinction between under and overcorrection.
} 


$$
s=\frac{S}{A}=\frac{A-R}{A}=1-\frac{R}{A}=1-r
$$

with

Clearly

$$
s_{0}=\frac{A-R_{0}}{A}
$$

and

$$
s+r=1
$$

$$
s_{0}+r_{0}=1
$$

Any of the four representations, R, S, r and s, can then be chosen to graphically display the behavior of residual astigmatism as a function of mismatch and/or angle of misalignment: a) The residual error in diopters as a function of the increasing angle of misalignment, $R(\lambda)$, typically an increasing function of $\lambda, b$ ) a residual error normalized to the value of $A$ in diopters, $\mathrm{r}(\lambda)$, and where values are thus fractional, also an increasing function, c) The amount of astigmatism having been corrected $S(\lambda)=A$ - R a decreasing function of $\lambda$ and $d$ ) the fractional correction of astigmatism being corrected that is also a decreasing curve as a function of increasing angle $\lambda, s(\lambda)$.

Figure 4 illustrates how one translates one representation to another by elementary algebraic operations. Results can be illustrated in one or more of the graphs of $\mathrm{R}, \mathrm{S}=\mathrm{A}-\mathrm{R}, \mathrm{r}$ or $\mathrm{s}$, as a function of $\lambda$ and we will usually indicate which representation is chosen and if we are in presence of under or overcorrection, unless the context makes it clear. The four options are illustrated in Figure 5 for the case of matching $\mathrm{L}$ and A.

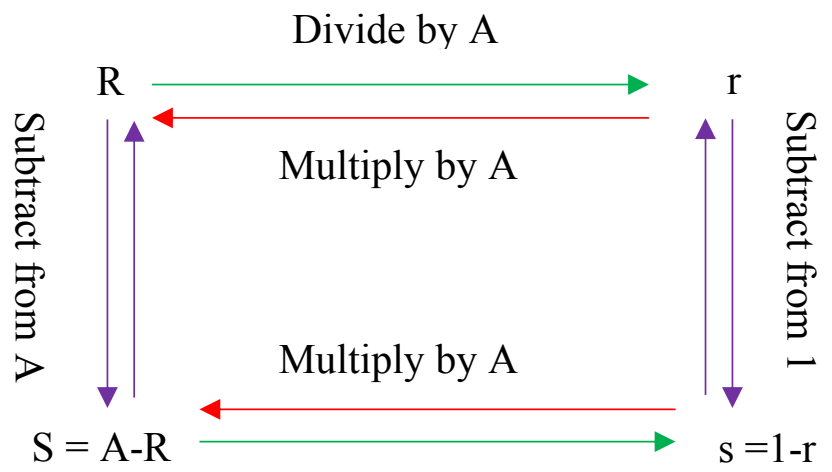

Divide by A

Figure 4 Navigating between 4 equivalent representations of residual astigmatism, 1) the full residual, $R$, 2) the fractional residual $r$, with respect to A, astigmatism to be corrected, 3) the magnitude of astigmatism having been corrected, $S$ and 4) the fractional correction, $s$, with respect to $A$. 


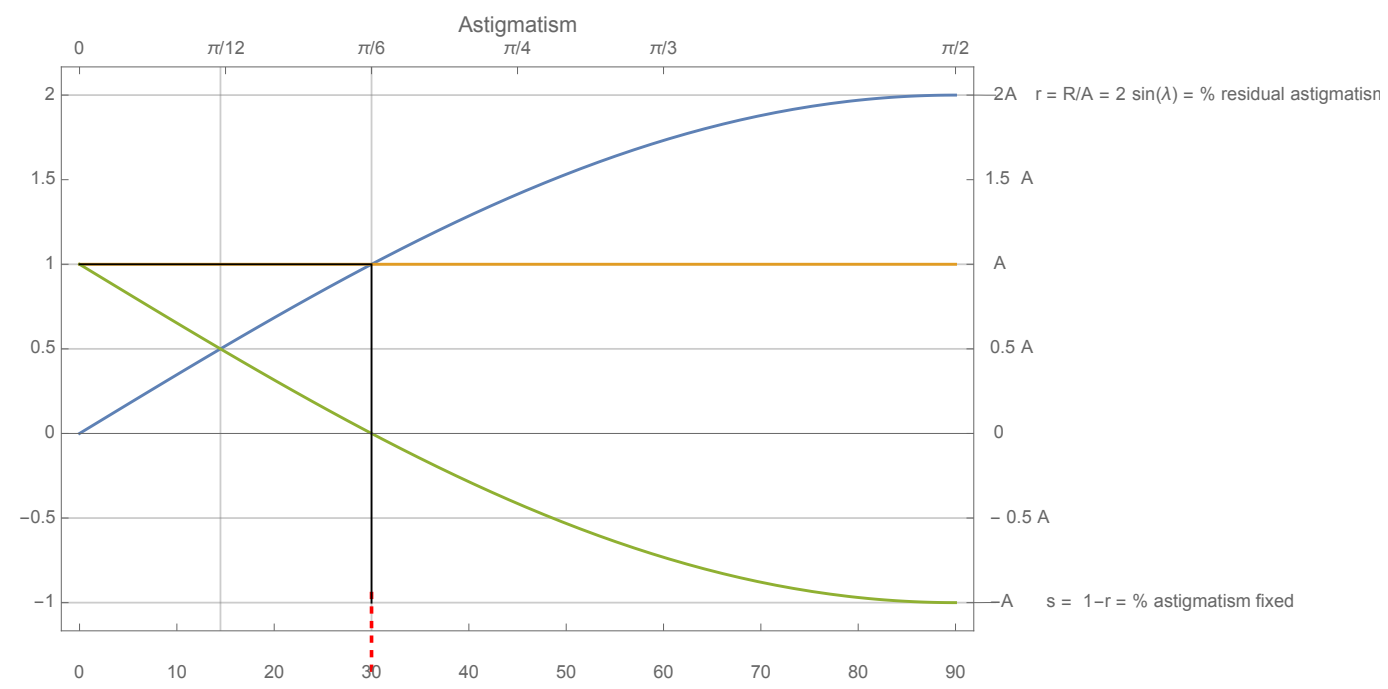

Figure 5 An astigmatism of cylinder value $=$ A diopters, being corrected by a $\mathrm{tIOL}$ of $L=A$ diopters as it rotates, results in residual astigmatism represented as magnitude of residual astigmatism (ascending curve), astigmatism corrected (descending curve) as full value of astigmatism (right scale) or its fractional representation wrt A (left scale).

A normalized increasing residual curve was given computationally for the matched case by Sanders, Grabow and Sheperd ${ }^{3}$ in 1992, with no functional dependence given explicitly but a sine dependence hinted at. That interesting chapter entitled "The Toric IOL" that ushered in the manufacturing and FDA approval of toric IOLs in the US dealt with a non toric STAAR IOL that was marked to examine rotational stability and simulate what would happen once tIOLs became available. In 2002, Till et al ${ }^{5}$ presented a percent correction of astigmatism as a function of angle of rotation, also restricted to the matched case, and also numerically selecting or highlighting discrete values every 10 degrees and connecting them, with no mention of a specific functional dependence. Felipe et al. presented a normalized increasing astigmatism curve for the matched case and gave a functional dependence in the context of a discussion of matrix methods ${ }^{29}$.

\section{RESULTS}

The expressions $2 \mathrm{a}$ and $2 \mathrm{~b}$ can add significant insight to our understanding of tIOL astigmatism mismatch and misalignment. In particular, we observe the following

1) In the absence of misalignment, $(\lambda=0)$, we obtain the expected $R_{0}$ term, in all cases of mismatch.

2) In the absence of mismatch $\left(\mathrm{L}=\mathrm{A}, \mathrm{R}_{0}=0\right)$ and the presence of misalignment, we obtain the expected behavior of $\mathrm{R}$ as the angle of the tIOL changes, namely

$$
R=2 A \sin \lambda
$$

including when $\mathrm{R}=\mathrm{A}(\mathrm{r}=1)$ leading to $\sin \Delta=1 / 2$ and the often cited $\Delta=30$ degrees. 
medRxiv preprint doi: https://doi.org/10.1101/2020.06.09.20126987; this version posted June 16, 2020. The copyright holder for this preprint (which was not certified by peer review) is the author/funder, who has granted medRxiv a license to display the preprint in perpetuity.

It is made available under a CC-BY-NC-ND 4.0 International license .

3) In the presence of both mismatch and misalignment we obtain the sum of two terms corresponding to mismatch only ( $\mathrm{R}_{0}$ but no $\lambda$ ) and misalignment only ( $\lambda$ but no $\mathrm{R}_{0}$ ), in addition to a cross term that depends on both mismatch $\mathrm{R}_{0}$ and misalignment $\lambda$.

4) The cross term has a different and opposite sign contribution to the residual astigmatism in the case of undercorrection compared to the case of overcorrection.

5) As a consequence of 4) and while the behavior of the residual astigmatism is symmetrical with respect to the side on which misalignment occurs, it is not symmetrical with respect to the side on which mismatch occurs.

We now turn our attention to the general case $L \neq A$ and compare it to the special case $L=A$. From Equations 3(a) and 3(b) we plot $r$ as a function of angle $\lambda$ of misalignment for cases of a perfect match of $\mathrm{A}$ to $\mathrm{L}(\mathrm{A}=\mathrm{L})$ and two for a mismatch of 0.5 (i.e. $r_{0}=\frac{R_{0}}{A}=\frac{|A-L|}{A}=0.5$ ) Figure 6. As an alternate representation, we also plot, $s$, the percent loss of astigmatism correction as a function of $\lambda$. As illustrated in Figure 7, these representations are equivalent but one or the other may be more appealing to the intuition of different readers.

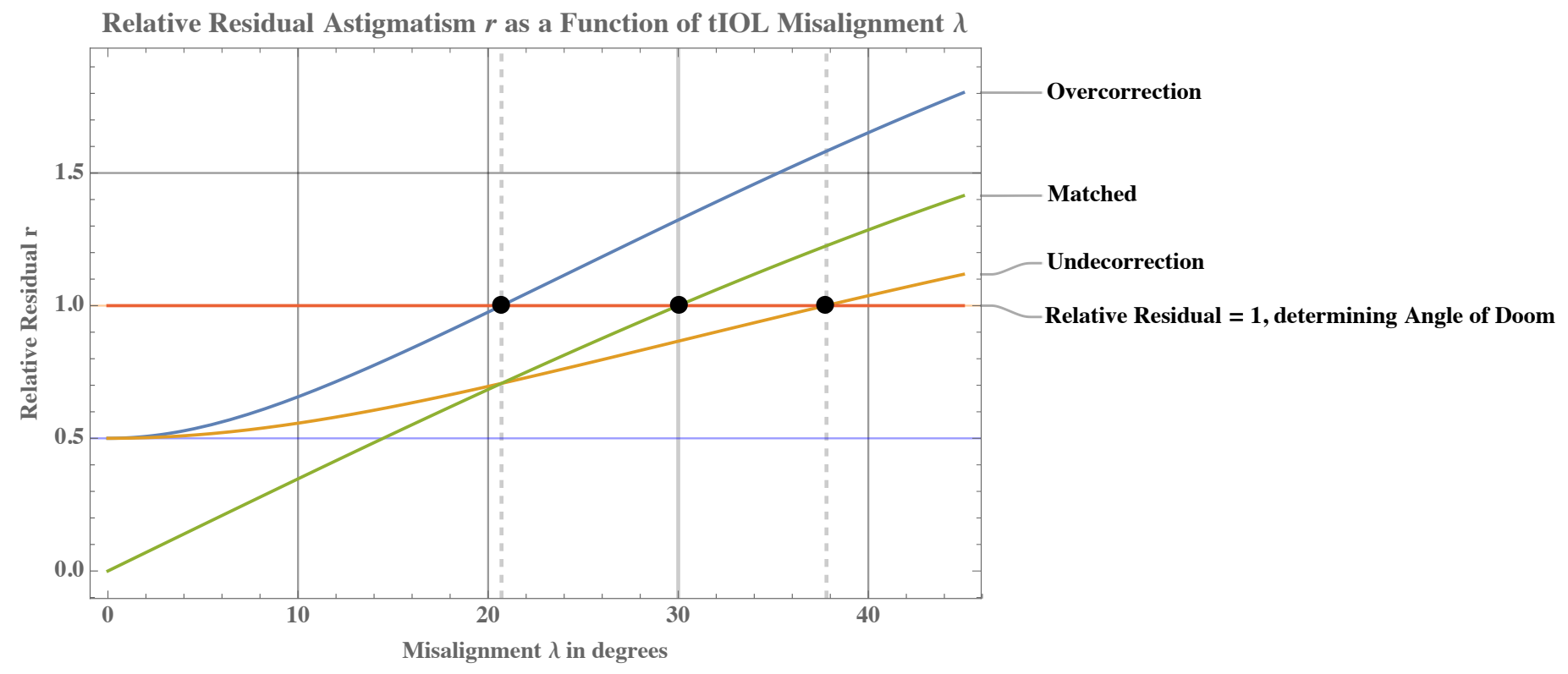

Figure 6 Relative residual error as a function of angle of misalignment for matched case (green) as well as over (blue) and undercorrection(orange). Angle of doom determined by intersection of each curve with $r=1$. Observe that for undercorrection $\Delta$ $\sim 40$ degrees and for overcorrection $\Delta \sim 20$ degrees. 


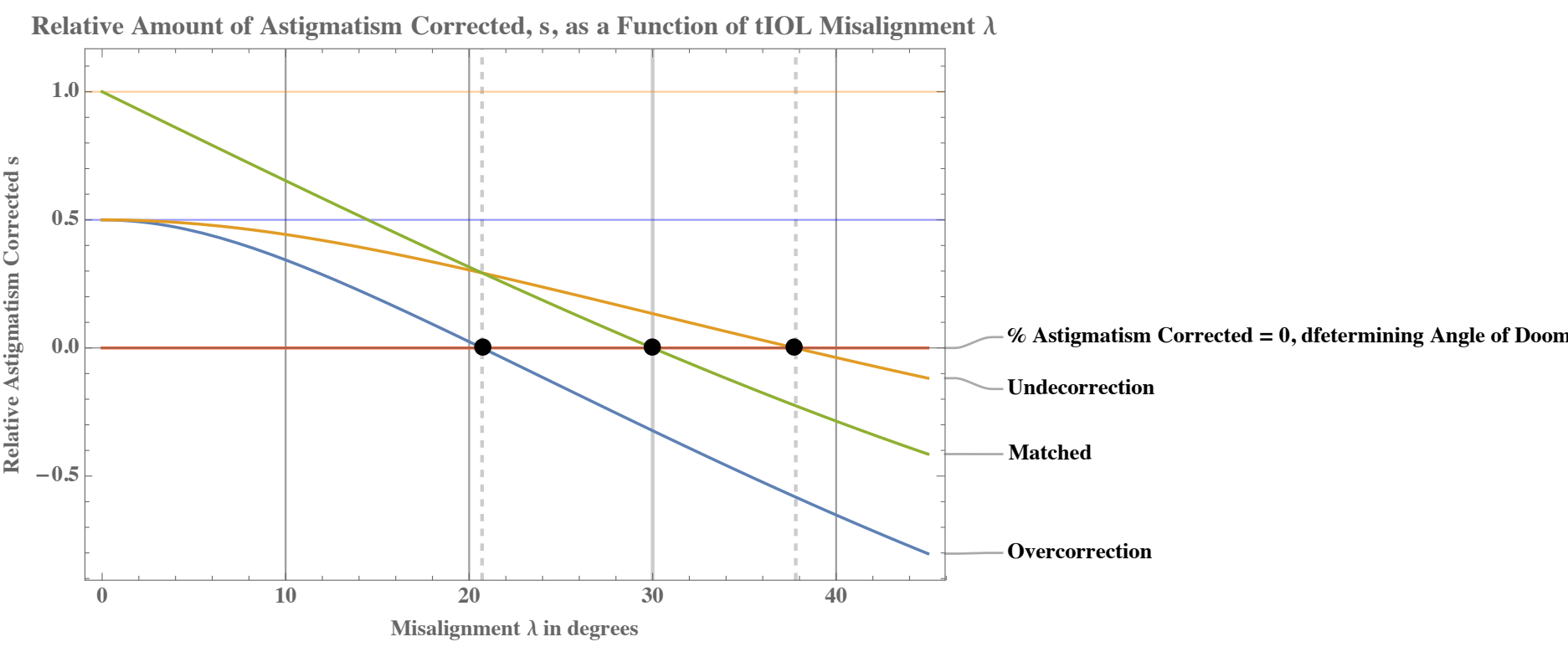

Figure 7 Relative amount of astigmatism corrected as a function of misalignment for matched case (green) as well as over (blue) and undercorrection(orange). Angle of doom determined by intersection of each curve with $s=0$. Clearly here too we observe that for undercorrection $\Delta \sim 40$ degrees and for overcorrection $\Delta \sim 20$ degrees.

The following observations can be made

1) In the case of perfect match, the rise of the residual $r$ as a function of angle of misalignment is nearly linear. This corresponds to the nearly linear portion of the sine function ${ }^{2}$. In the $s$ representation a corresponding early linear decay in \% corrected astigmatism is seen.

2) For a perfect match, at 30 degrees, $r=1$, meaning the residual is now equal to the original value of the astigmatism to be corrected. This is the known and often repeated result that captures this very special case but is far from representing most realistic surgical situations. In other words for the matched case, the angle of doom $\Delta=30^{\circ}$.

3) The residual astigmatism in the overcorrection case L $>$ A rises faster than it does for the undercorrection case $\mathrm{L}<\mathrm{A}$ as the angle is rotated and the residual always remains larger. The angle of doom is thus reached earlier, and possibly much earlier, for the overcorrection case than for the matched or undercorrected case. For the specific $50 \%$ overcorrection or undercorrection displayed, we have $\Delta$ at just less than $21^{\circ}$ in the case of overcorrection and $\Delta$ nearly $38^{\circ}$ in the case of undercorrection. We can see that in quite realistic cases of overcorrection, the angle of doom can be about 10 degrees smaller than usually claimed. Similarly in cases of undercorrection, it can be about 10 degrees larger than the commonly taught value of 30 degrees.

${ }^{2}$ Because $\sin \mathrm{x} \sim \mathrm{x}$ is a good approximation up to about 30 degrees, one can write

$\frac{R}{A}=\frac{2 \pi \lambda}{180} \sim \frac{\lambda}{30} \sim 0.033 \lambda=3.3 \% \lambda$

where $\lambda$ is in degrees. These results ("Total loss of astigmatic correction at $30^{\circ}$ and $3.3 \%$ loss per degree of rotation") are often cited without clarifying either of the underlying assumptions, namely, magnitude match, $\mathrm{L}=\mathrm{A}$, and the linearization of the sine function. It is important to note that this approximation becomes increasingly poor beyond 30 degrees. 
medRxiv preprint doi: https://doi.org/10.1101/2020.06.09.20126987; this version posted June 16, 2020. The copyright holder for this preprint

(which was not certified by peer review) is the author/funder, who has granted medRxiv a license to display the preprint in perpetuity.

It is made available under a CC-BY-NC-ND 4.0 International license .

4) The cases $r_{0}=0.5$ and $r_{0}=0$ actually cross, with the graph for undercorrection yielding less residual past the intersection point. Crossing occurs also around $21^{\circ}$ in this case as indicated on the graph. This is an indication that for a certain degree of misalignment, undercorrection may actually be preferred not only to overcorrection, but also to an exact match of the tIOL to the astigmatism to be corrected. One can easily show that for $\mathrm{r}_{0}=0.1$, undercorrection becomes preferable to perfect match at about 9 degrees, for the case $r_{0}=0.2$, at about 13 degrees and for $r_{0}=0.3$ it occurs at about 16 degrees. A full discussion will be presented in a companion paper and its clinical and surgical consequences will be shown to be significant.

\section{Predicting the Angle of Doom: When do we totally lose the effect of astigmatic correction?}

The question is usually asked in terms of an angle of alignment and/or rotation of the tIOL relative to the presumed meridian of the astigmatism to be corrected. The answer clearly depends on L, and more specifically on $\frac{L}{A}$

Returning to Equation (1) we now consider A and L having arbitrary values, not necessarily equal. We first establish the conditions for $R=A$. Recalling Equation (1)

$$
R^{2}(\lambda)=A^{2}+L^{2}-2 A L \cos 2 \lambda
$$

We divide by $\mathrm{A}^{2}$, define $\rho=\frac{L}{A}$ and recall that $r=\frac{R}{A}$, yielding

$$
r^{2}(\lambda)=1+\rho^{2}-2 \rho \cos 2 \lambda
$$

Requiring $\mathrm{R}=\mathrm{A}$, implies $r=1$, and results in the condition for $\lambda=\Delta$, the angle of doom,

Or

$$
\rho-2 \cos 2 \Delta=0
$$

$$
\cos 2 \Delta=\frac{\rho}{2}
$$

A similar condition, slightly less elegantly expressed, was given by Felipe et $\mathrm{al}^{29}$ in the context of matrix methods with few of its implications explored.

Here we propose to 1) explore a few key values before 2) giving a full expansion of the function and the subject surrounding it, by explicitly inverting Equation (5) to give the values of $\Delta$ as $a$ function of $\rho$ and then 3 ) provide an excellent approximation of $\Delta$, for both under and overcorrection, that can readily be used in most clinical situations.

For $\rho=0$, the "non toric" case, we have $2 \Delta=90$ degrees and $\Delta=45$ degrees, the proper limit presented geometrically in an earlier section (see Figure 2). The effect of a very low correcting tIOL will be totally lost at 45 degrees misalignment or less. For $\rho=1$, the matched case, and the one usually discussed or assumed in much of the literature, we have $2 \Delta=$ 60 degrees and thus $\Delta=30$ degrees, the usually quoted result. Finally for $\rho=2$, ie overcorrection by the full initially present astigmatism, A, we have already reached "doom" with no need for misalignment and indeed $\cos 2 \Delta=1$ yields $\Delta=0$, as expected. 
medRxiv preprint doi: https://doi.org/10.1101/2020.06.09.20126987; this version posted June 16, 2020. The copyright holder for this preprint (which was not certified by peer review) is the author/funder, who has granted medRxiv a license to display the preprint in perpetuity.

One can solve Equation (5) for $\Delta$ and plot the result (Figure 8) as a function of $\rho$ for $0 \leq \rho \leq 2$

$$
\Delta=\frac{1}{2} \arccos \left(\frac{\rho}{2}\right)
$$

Angle of DOOM $\triangle$ as a function of the ratio $\rho=\mathrm{L} / \mathrm{A}$

Angle of Doom $\Delta$ in degrees

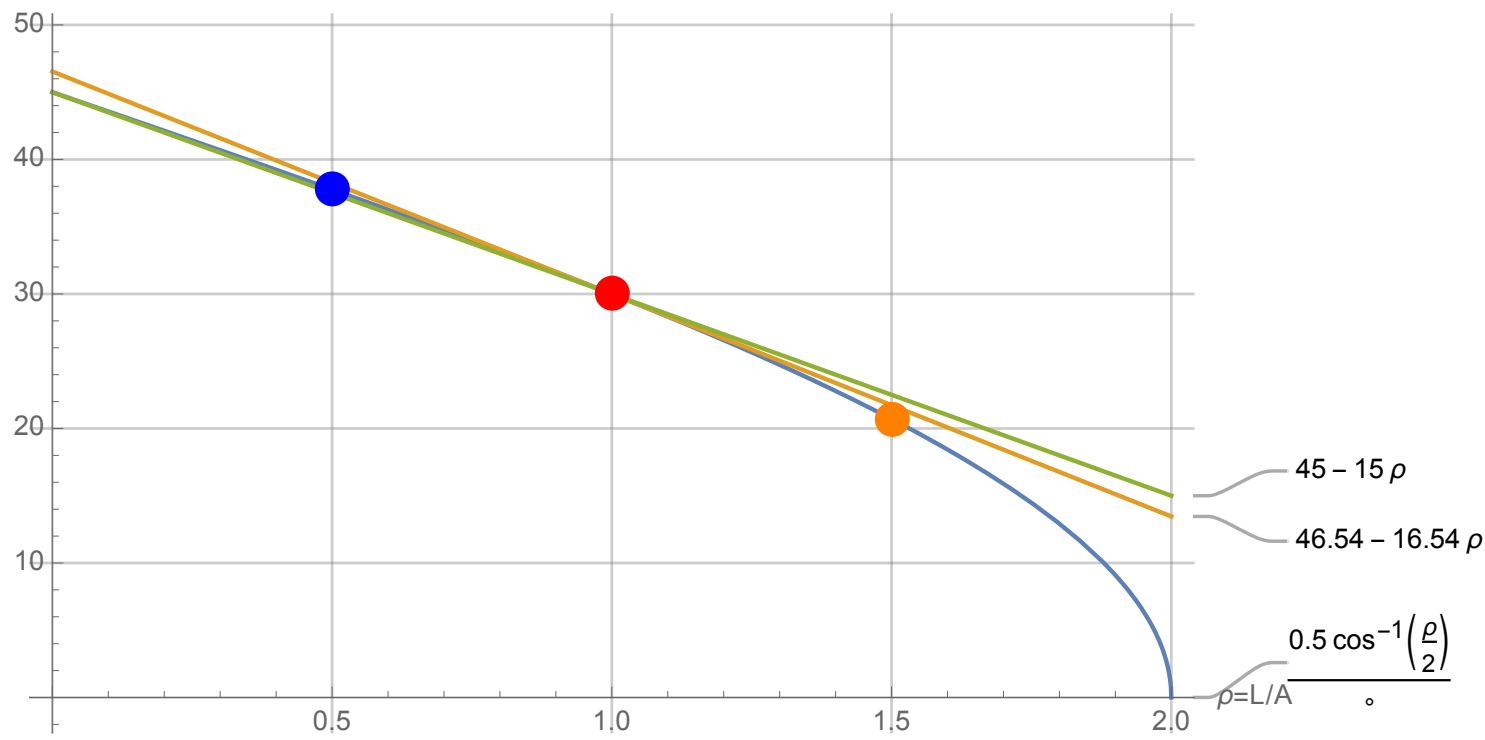

Figure 8 Angle of Doom $\Delta$ as a function of $\rho=\frac{L}{A}$ with linearization around $(1,30)$

From Figure (8) one confirms the cancellation angle is 30 degrees for $\rho=\frac{L}{A}=1$ as shown but more interestingly that the value of $\Delta$ can be significantly larger for $\mathrm{L}<\mathrm{A}$ and significantly smaller for $\mathrm{L}>\mathrm{A}$, as illustrated in specific examples in the introduction. Here again we can see that a $50 \%$ undercorrected eye can extend the angle $\Delta$ to almost 40 degrees while a $50 \%$ overcorrection can reduce $\Delta$ to about 20 degrees, as shown explicitly in Figure 6 and Figure 7 .

The function in Equation (6) as seen on graph in Figure 8 can now be linearized by an expansion in a Taylor series around the value $\rho=\frac{L}{A}=1.0$ to yield $\Delta \cong 46.54-16.54 \rho$. This gives the correct value of 30 for $\rho=1$ and is a very good practical approximation for $\rho$ in the range between zero and 1.5 and excellent in the clinically practical range of 0.5 to 1.5 . The more practical $\sim 45-15 \rho$ has the additional advantage of matching the limit at $\rho=0$ to its correct expected 45 degrees limit, while also predicting the 30 degrees of the "classic" $\rho=1$ case. In any case the approximation is excellent in the full range of $0<\frac{L}{A}<1.5$ and it is clear that past a value of 1.5 the angle falls very rapidly to zero consistent with the fact that the correcting $\mathrm{L}$ value is nearing double the value of the astigmatism to be corrected. For clinical estimate in the range $0<\rho=\frac{L}{A}<1.5$ we thus adopt

which can be rewritten

$$
\Delta \text { (degrees) } \sim 45-15 \frac{L}{A}
$$


medRxiv preprint doi: https://doi.org/10.1101/2020.06.09.20126987; this version posted June 16, 2020. The copyright holder for this preprint

$$
\Delta \text { (degrees) } 45-15 \frac{R_{0}+A}{A}=30-15 r_{0}
$$

Or, for an overcorrection

$$
\Delta \approx 30-15 \omega
$$

Similarly for undercorrection a change of variable yields

$$
\Delta \text { (degrees) } \sim 45-15 \frac{-R_{0}+A}{A}=30+15 \mathrm{r}_{0}
$$

and we can express $\Delta$ for an undercorrection as

$$
\Delta \approx 30+15 u
$$

These expressions for $\Delta$ are centered on 30 degrees, the value often cited, but make it clear that overcorrection would result in a significantly smaller angle of doom and conversely, undercorrection extends the range of misalignment for which some astigmatic correction is still beneficial. The expressions are very practical and facilitate the immediate visualization of the effect and give an accurate estimate in the most relevant clinical range of $0 \leq L \leq 1.5 \mathrm{~A}$ covering a continuous range including both significant under and overcorrection. As pointed out previously they could be expressed in one equation with a sign indicating the undercorrecting or overcorrecting nature of the situation. For the sake of clarity of this and further discussions we prefer to continue to separately and explicitly display the sign dependence on over and undercorrection.

\section{DISCUSSION AND CONCLUSION}

This work is part of a tradition of description, analysis and development of computational tools dealing with astigmatism in the human eye that extends back more than two centuries and, of its surgical correction with toric intraocular lenses that extends more than two decades.

Improvement in analysis, surgical technique and quality of the tIOLs available have brought us much closer to the goal of simultaneous elimination of undesirable refractive error at the time of cataract surgery. However, a belief has persisted as to the exact quantitative nature of the effect of a misalignment and rotation of the tIOL and the angle, here designated as the "angle of doom, $\Delta$ ", where the amount of correction provided by the tIOL reduces to zero. This angle is consistently believed to be 30 degrees, even though some computational studies in the context of clinical refraction, and more recently surgical correction, have indicated it may be otherwise. Using the simplest tools for analyzing astigmatism we give an exact treatment that shows convincingly that a clear distinction must be made between under and over correction. Our analysis also results in an exact expression for $\Delta$ as well as a clinically relevant and convenient approximation centered on 30 degrees, the value commonly believed to be the correct value. This work and a companion paper should contribute to the establishment of a rational approach to the selection of tIOLs for the surgical correction of astigmatism in general and especially at the time of refractive cataract surgery. 
medRxiv preprint doi: https://doi.org/10.1101/2020.06.09.20126987; this version posted June 16, 2020. The copyright holder for this preprint (which was not certified by peer review) is the author/funder, who has granted medRxiv a license to display the preprint in perpetuity. It is made available under a CC-BY-NC-ND 4.0 International license .

\section{References}

1. Visser N, Bauer NJC, Nuijts RMMA. Toric intraocular lenses: Historical overview, patient selection, IOL calculation, surgical techniques, clinical outcomes, and complications. J Cataract Refract Surg. 2013. doi:10.1016/j.jcrs.2013.02.020

2. Kramer BA, Berdahl JP, Hardten DR, Potvin R. Residual astigmatism after toric intraocular lens implantation: Analysis of data from an online toric intraocular lens backcalculator. J Cataract Refract Surg. 2016. doi:10.1016/j.jcrs.2016.09.017

3. Sanders DR, Grabow HB SJ. The Toric IOL. In: Gills JP, Martin RB SD, ed. Sutureless Cataract Surgery: An Evolution Toward Minimally Invasive Technique. Thorofare, NJ: Slack Inc.; 1992.

4. Novis C. Astigmatism and toric intraocular lenses. Curr Opin Ophthalmol. 2000. doi:10.1097/00055735-200002000-00007

5. Till JS, Yoder PR, Wilcox TK, Spielman JL. Toric intraocular lens implantation: 100 Consecutive cases. J Cataract Refract Surg. 2002;28(2):295-301. doi:10.1016/S08863350(01)01035-5

6. Chang DF. Early rotational stability of the longer Staar toric intraocular lens: Fifty consecutive cases. J Cataract Refract Surg. 2003. doi:10.1016/S0886-3350(02)01843-6

7. Tyson S. Refractive lens exchange with foldable toric intraocular lens. Evidence-Based Ophthalmol. 2009. doi:10.1097/IEB.0b013e3181b93ca8

8. Berdahl JP, Hardten DR. Comment on "Residual astigmatism after toric intraocular lens implantation." J Cataract Refract Surg. 2012;38(4):730-731.

doi:10.1016/j.jcrs.2012.01.018

9. Mencucci R, Favuzza E, Guerra F, Giacomelli G, Menchini U. Clinical outcomes and rotational stability of a 4-haptic toric intraocular lens in myopic eyes. J Cataract Refract Surg. 2014. doi:10.1016/j.jcrs.2013.12.024

10. Kessel L, Andersen J, Tendal B, Erngaard D, Flesner P, Hjortdal J. Toric Intraocular Lenses in the Correction of Astigmatism During Cataract Surgery. Ophthalmology. 2016. doi:10.1016/j.ophtha.2015.10.002

11. Kaur M, Shaikh F, Falera R, Titiyal J. Optimizing outcomes with toric intraocular lenses. Indian J Ophthalmol. 2017. doi:10.4103/ijo.IJO_810_17

12. Lee BS, Chang DF. Comparison of the Rotational Stability of Two Toric Intraocular Lenses in 1273 Consecutive Eyes. Ophthalmology. 2018;125(9):1325-1331.

doi:10.1016/j.ophtha.2018.02.012

13. Uy HS, Tesone-Coelho C. Rotational stability of a new multicomponent intraocular lens. Clin Ophthalmol. 2019. doi:10.2147/OPTH.S214835

14. Moon J, Yoon CH, Kim MK. Comparative effects of various types of toric intraocular lenses on astigmatism correction. BMC Ophthalmol. 2020. doi:10.1186/s12886-020$01439-4$

15. Li S, Li X, He S, et al. Early Postoperative Rotational stability and its related factors of a single-piece acrylic toric intraocular lens. Eye. 2020. doi:10.1038/s41433-019-0521-0

16. Gabra LG, Sayegh SI. A Direct Method for Determining Toricity Ratios of Toric Intraocular Lens Calculators. Sci Rep. 2018;8(1). doi:10.1038/s41598-018-22591-4

17. Visser N, Berendschot TTJM, Verbakel F, De Brabander J, Nuijts RMMA. Comparability and repeatability of corneal astigmatism measurements using different measurement 
medRxiv preprint doi: https://doi.org/10.1101/2020.06.09.20126987; this version posted June 16, 2020. The copyright holder for this preprint (which was not certified by peer review) is the author/funder, who has granted medRxiv a license to display the preprint in perpetuity. It is made available under a CC-BY-NC-ND 4.0 International license .

technologies. J Cataract Refract Surg. 2012. doi:10.1016/j.jcrs.2012.05.036

18. Ferreira TB, Ribeiro FJ. Comparability and repeatability of different methods of corneal astigmatism assessment. Clin Ophthalmol. 2018. doi:10.2147/OPTH.S146730

19. Hill W. Expected effects of surgically induced astigmatism on AcrySof toric intraocular lens results. J Cataract Refract Surg. 2008. doi:10.1016/j.jcrs.2007.10.024

20. Sayegh SI, Al-Heeti A. Three Shades of Grey: Toric IOL Choices and Principled Uncertainty. In: Meeting of The American Society of Cataract and Refractive Surgeons (ASCRS) 2019. San Diego, CA; 2019.

21. Potvin R, Kramer BA, Hardten DR, Berdahl JP. Toric intraocular lens orientation and residual refractive astigmatism: An analysis. Clin Ophthalmol. 2016.

doi:10.2147/OPTH.S114118

22. Spaw AT, Ennis BW, Spaw LP. Laparoscopic hernia repair: the anatomic basis. $J$ Laparoendosc Surg. 1991. doi:10.1089/1ps.1991.1.269

23. Euler L. Recherches sur la Courbure des Surfaces. Mémoire l'Académie des Sci Berlin. $1767 ; 16: 119-143$.

24. Stokes GG. On a Mode of Measuring the Astigmatism of a Defective Eye. Trans 19th Meet Br Assoc Adv Sci (Birmingham Meet 1849). 1850:10-11.

25. Stokes GG. On a Mode of Measuring the Astigmatism of a Defective Eye. In: Mathematical and Physical Papers by George Gabriel Stokes, Vol 2. Cambridge: University Press; 1883:172-175.

26. Linksz A. Determination of Axis and Amount of Astigmatic Error by Rotation of Trial Cylinder. Arch Ophthalmol. 1942. doi:10.1001/archopht.1942.00880100066005

27. Guyton DL. Prescribing cylinders: The problem of distortion. Surv Ophthalmol. 1977. doi:10.1016/0039-6257(77)90054-6

28. Ma JJK, Tseng SS. Simple method for accurate alignment in toric phakic and aphakic intraocular lens implantation. J Cataract Refract Surg. 2008.

doi:10.1016/j.jcrs.2008.04.041

29. Felipe A, Artigas JM, Díez-Ajenjo A, García-Domene C, Alcocer P. Residual astigmatism produced by toric intraocular lens rotation. J Cataract Refract Surg. 2011. doi:10.1016/j.jcrs.2011.04.036

30. Yae Y, Kubota T. A New Method for Calculating Residual Astigmatism Produced by Toric Intraocular Lens Rotation. Ophthalmol Res An Int J. 2014. doi:10.9734/or/2014/12067

31. Felipe A, Artigas J. Reply to Comment on "Residual astigmatism after toric intraocular lens implantation." J Cataract Refract Surg. 2012;38(4):731-732.

32. Sayegh SI. It Ain't 30. Toric IOL Rotation and the (smaller) Angle of Doom. In: Meeting of The American Society of Cataract and Refractive Surgeons (ASCRS) 2020. Boston, MA; 2020.

33. Beheregaray S, Goggin M, LaHood B. Astigmatic overcorrection and axis flip for targeting minimal remaining refractive astigmatism with toric intraocular lenses. $J$ Cataract Refract Surg. 2018;44(1):91-97. doi:10.1016/j.jcrs.2017.11.004 